\title{
Randomised controlled trial of intrapleural streptokinase in community acquired pleural infection
}

\author{
Robert J O Davies, Zoë C Traill, Fergus V Gleeson
}

\begin{abstract}
Background - Standard treatment for pleural infection includes catheter drainage and antibiotics. Tube drainage often fails if the fluid is loculated by fibrinous adhesions when surgical drainage is needed. Streptokinase may aid the process of pleural drainage, but there have been no controlled trials to assess its efficacy.
\end{abstract}

Methods - Twenty four patients with infected community acquired parapneumonic effusions were studied. All had either frankly purulent/culture or Gram stain positive pleural fluid (13 cases; $54 \%$ ) or fluid which fulfilled the biochemical criteria for pleural infection. Fluid was drained with a $14 \mathrm{~F}$ catheter. The antibiotics used were cefuroxime and metronidazole or were guided by culture. Subjects were randomly assigned to receive intrapleural streptokinase, 250000 IU daily, or control saline flushes for three days. The primary end points related to the efficacy of pleural drainage - namely, the volume of pleural fluid drained and the chest radiographic response to treatment. Other end points were the number of pleural procedures needed and blood indices of inflammation. Results - The streptokinase group drained more pleural fluid both during the days of streptokinase/control treatment (mean (SD) 391 (200) $\mathrm{ml}$ versus 124 (44) $\mathrm{ml}$; difference $267 \mathrm{ml}, 95 \%$ confidence interval (CI) 144 to $390 ; p<0.001)$ and overall (2564 (1663) $\mathrm{ml}$ versus 1059 (502) $\mathrm{ml}$; difference $1505 \mathrm{ml}, 95 \%$ CI 465 to $2545 ; \mathrm{p}<0.01)$. They showed greater improvement on the chest radiograph at discharge, measured as the fall in the maximum dimension of the pleural collection $(6.0(2.7) \mathrm{cm}$ versus 3.4 $(2.7) \mathrm{cm}$; difference $2.9 \mathrm{~cm}, 95 \%$ CI 0.3 to $4.4 ; p<0.05)$ and the overall reduction in pleural fluid collection size $(p<0.05$, twotailed Fisher's exact test). Systemic fibrinolysis and bleeding complications did not occur. Surgery was required by three control patients but none in the streptokinase group.

Conclusions - Intrapleural streptokinase probably aids the treatment of pleural infections by improving pleural drainage without causing systemic fibrinolysis or local haemorrhage.

(Thorax 1997;52:416-421)

Keywords: pneumonia, pleural empyema, streptokinase, fibrinolysis, pleural effusion.
Secondary pleural infection is an important complication of pneumonia. Over $40 \%$ of patients with community acquired pneumonia develop an associated pleural effusion ${ }^{12}$ and about $15 \%$ of these become secondarily infected. ${ }^{12}$ In the UK pleural infection has a mortality of about $20 \%{ }^{3}$ The transition of a simple effusion to the infected state is heralded by fibrin deposition in the pleural cavity ${ }^{4}$ and by indicators of white cell and bacterial metabolism within the effusion fluid (falling $\mathrm{pH}$ and glucose levels and rising levels of lactate dehydrogenase). ${ }^{15-8}$ Once secondary infection of the pleural space has occurred, the mainstay of management is effective drainage of the pleural collection. ${ }^{910}$

Traditionally, drainage of the pleural space has been achieved by simple aspiration, catheter drainage, or thoracotomy with decortication or rib resection. ${ }^{9}$ Of these approaches, surgical procedures achieve the best drainage but carry an obvious morbidity. Less invasive drainage techniques are often limited by the loculation of pleural fluid by fibrinous septae, the presence of fibrinous clots within the empyema fluid which may block chest drains, and the development of an infected fibrinous pleural "rind". 9 .

Uncontrolled studies have suggested that intrapleural streptokinase may improve the drainage of infected pleural effusions by lysis of the intrapleural fibrinous adhesions. ${ }^{11-19}$ None of these series includes a control group which makes interpretation of their results difficult. The weaknesses of these series means that this form of treatment is still controversial ${ }^{20}$ and the need for a controlled study which assesses the early use of streptokinase has been emphasised. ${ }^{3910}$ This paper reports the results of a randomised comparison of intrapleural streptokinase given at diagnosis with control saline flushes in patients with complicated parapneumonic effusion and empyema.

\section{Methods}

SUBJECTS

Twenty four subjects (17 men) were studied. All presented to one unit over three years with community acquired pneumonia associated with features of systemic sepsis (fever, raised white blood cell count, and C reactive protein) and a pleural effusion requiring drainage.

Inclusion criteria for entry to the study were purulent pleural fluid, pleural fluid Gram stain or culture positive for bacteria, $\mathrm{pH}$ of pleural fluid of $<7.1$, pleural fluid concentrations of 
lactate dehydrogenase $>1000 \mathrm{IU} / 1$, pleural fluid/blood glucose ratio $<0.25$, or loculation or septation of pleural fluid on computed tomographic (CT) and ultrasound scanning. Exclusion criteria were age $<18$ or $>90$ years, treatment with streptokinase by any route in the previous two years, bleeding diathesis, stroke or significant haemorrhage in the preceding six months, known sensitivity to streptokinase, or any disease making survival at two months unlikely.

PROTOCOL

Subjects were randomised in an age stratified manner to receive streptokinase or to the control group. Temperature, white blood cell count, prothrombin ratio (expressed as the International Normalised Ratio, INR), and levels of $\mathrm{C}$ reactive protein were recorded. The duration of symptoms to diagnosis of the infected pleural collection was noted. Posteroanterior and lateral chest radiography, contrast enhanced thoracic CT scanning and pleural ultrasound scans were performed. A 14 French van Sonnenberg catheter ${ }^{21}$ was then positioned in either the most dependent portion of the collection or the largest locule under ultrasound guidance. The catheter was inserted by two radiologists who were unaware of the group to which the subject had been randomised. This was connected to an underwater drain and kept on continuous suction at $-20 \mathrm{~cm} \mathrm{H}_{2} \mathrm{O}$ (except during saline or streptokinase injection) until removal. All catheters were flushed six hourly with $20 \mathrm{ml}$ of saline to maintain their patency. ${ }^{21}$

For the three days following catheter insertion the streptokinase group received $250000 \mathrm{IU}$ intrapleural streptokinase in $20 \mathrm{ml}$ saline in place of one of the saline flushes. After streptokinase injection the chest catheter was closed off for two hours and then returned to suction. Patients receiving control therapy continued saline flushes as usual.

Temperature and pleural fluid drainage were recorded daily to discharge and chest drain removal, respectively. Blood white cell count, $\mathrm{C}$ reactive protein levels and prothrombin ratio (INR) were recorded at baseline, daily for the first four days of treatment, and then twice weekly to discharge. The posteroanterior and lateral chest radiographs were repeated at discharge. The total duration of hospital stay was recorded.

All patients received antibiotics. If cultures were negative these consisted of cefuroxime ( $1500 \mathrm{mg}$ intravenously three times daily, reduced in renal impairment) and metronidazole ( $400 \mathrm{mg}$ orally three times daily) for at least five days and until afebrile, followed by combination amoxycillin $500 \mathrm{mg}$ three times a day and clavulanic acid $250 \mathrm{mg}$ three times a day until discharge. Where cultures were positive the antibiotics given were those appropriate for the organisms isolated and were continued until discharge.

The catheters were removed after the fifth day of treatment provided pleural drainage had fallen to $<150 \mathrm{ml}$ per day (including returned saline flushes) for two consecutive days. The duration of chest drainage was noted. After removal of the first catheter further thoracic aspiration or catheter drainage of residual fluid collections was at the discretion of the managing physician. The total number of pleural procedures for fluid drainage was noted.

The radiographs were consensus scored by two radiologists as a batch without knowledge of the randomisation group of the subject. The size of the pleural collection was measured at baseline in three ways: (1) the maximal linear dimension of the collection was measured from the posteroanterior and lateral chest radiographs; (2) the area of the hemithorax occupied by the collection was estimated to the nearest $10 \%$ from the posteroanterior chest radiograph; and (3) the volume of the hemithorax occupied by the collection was estimated to the nearest $10 \%$ on the thoracic CT scan. At discharge the maximal linear dimension of the pleural collection was remeasured and the overall reduction in the volume of the pleural collection from baseline to discharge was estimated from the posteroanterior and lateral chest radiographs as: no change, $>25 \%,>50 \%$, or $>75 \%$ reduction in volume.

TRIAL END POINTS AND WITHDRAWAL

The primary end points of the study related to the efficiency of pleural fluid drainage and were (1) volume of pleural fluid drained in total; (2) volume of pleural fluid drained during days $2-5$ of pleural drainage (first dose of streptokinase/ control given on day 2); and (3) improvement in chest radiograph from baseline to discharge. Secondary end points were (1) change in INR from baseline to its average over days $2-5$; (2) total number of pleural procedures for fluid drainage; (3) time until white blood cell count was $<12 \times 10^{9}$, C reactive protein levels were $<8 \mathrm{mg} / \mathrm{l}$ (normal range $<8 \mathrm{mg} / \mathrm{l}$ ), and the patient was consistently afebrile; and (4) duration of stay in hospital.

The study end point was discharge from hospital. Withdrawal before this point occurred in two circumstances - death of the patient or referral for surgery. Criteria for referral for surgery consisted of a progressive or unresponsive sepsis syndrome in the presence of a substantial residual pleural fluid collection.

STATISTICAL ANALYSIS

Statistical analysis was performed with the SAS statistical software package (SAS Institute, Cary, NC, USA). Unpaired $t$ testing was used unless otherwise stated.

\section{Results}

All the data analysis was performed after the end of data collection. Twenty four patients entered the study and were randomly assigned in an age stratified manner into the two study groups. The clinical and radiological baseline characteristics of the studied groups are presented in table 1 . The two groups were well matched by all the criteria examined. 
Table 1 Mean (SD) clinical characteristics of the study groups at randomisation

\begin{tabular}{lcc}
\hline & $\begin{array}{c}\text { Streptokinase } \\
(n=12)\end{array}$ & $\begin{array}{c}\text { Control } \\
(n=12)\end{array}$ \\
\hline Age & $62(23)$ & $60(23)$ \\
M:F & $9: 3$ & $8: 4$ \\
Maximal linear dimension of pleural collection on thoracic CT scan $(\mathrm{cm})$ & $8.3(2.6)$ & $6.6(2.1)$ \\
\% hemithorax occupied by pleural collection on PA chest radiograph & $35(22)$ & $28(19)$ \\
\% hemithorax occupied by pleural collection on thoracic CT scan & $40(23)$ & $28(16)$ \\
Admission temperature $\left({ }^{\circ} \mathrm{C}\right)$ & $37.8(0.70)$ & $37.6(0.40)$ \\
Total while blood cell count $\left(\times 10^{9}\right)$ & $17.9(8.0)$ & $12.2(6.8)$ \\
Prothrombin ratio (INR) & $1.25(0.13)$ & $1.18(0.9)$ \\
C reactive protein (mg/l) (normal <6 mg/l) & $194(83)$ & $206(107)$ \\
Pre-diagnosis symptom duration (days) & $27(17)$ & $35(26)$ \\
Number with frankly purulent fluid & 7 & 4 \\
Pleural pH & $6.95(0.32)$ & $6.97(0.32)$ \\
Pleural LDH (IU/l) & $2397(2296)$ & $4667(7847)$ \\
Pleural fluid to blood glucose ratio & $0.30(0.32)$ & $0.21(0.26)$ \\
Blood or pleural fluid Gram stain or culture positive & 6 & 7 \\
\hline
\end{tabular}

The differences between the groups were all non-significant.

MICROBIOLOGY

In 13 of the 24 subjects a microbiological diagnosis was established from pleural fluid Gram stain and culture or from blood culture. Streptococcus pneumoniae was identified in seven cases and Streptococcus milleri in three cases, in one of which the culture was mixed and included Arcanobacterium haemolyticum and Fusobacterium. Haemophilus influenzae, enterococci, and haemolytic streptococci Lancefield's group A were identified in one case each.

PLEURAL FLUID DRAINAGE

Two of the primary study end points related to the volume of pleural fluid drainage. Both of these showed highly significant differences between control and active treatment. The streptokinase treated group drained more pleural fluid during days 2-5 (streptokinase, mean (SD) 391 (200) ml versus control, 124 (44) $\mathrm{ml}$; difference $267,95 \%$ confidence interval (CI) 144 to $390 ; \mathrm{p}<0.001$ ) and more pleural fluid in total (2564 (1663) $\mathrm{ml}$ versus 1059 (502) $\mathrm{ml}$; difference $1505 \mathrm{ml}, 95 \%$ CI 465 to 2545 ; $p<0.01$; fig 1 ). Of the secondary
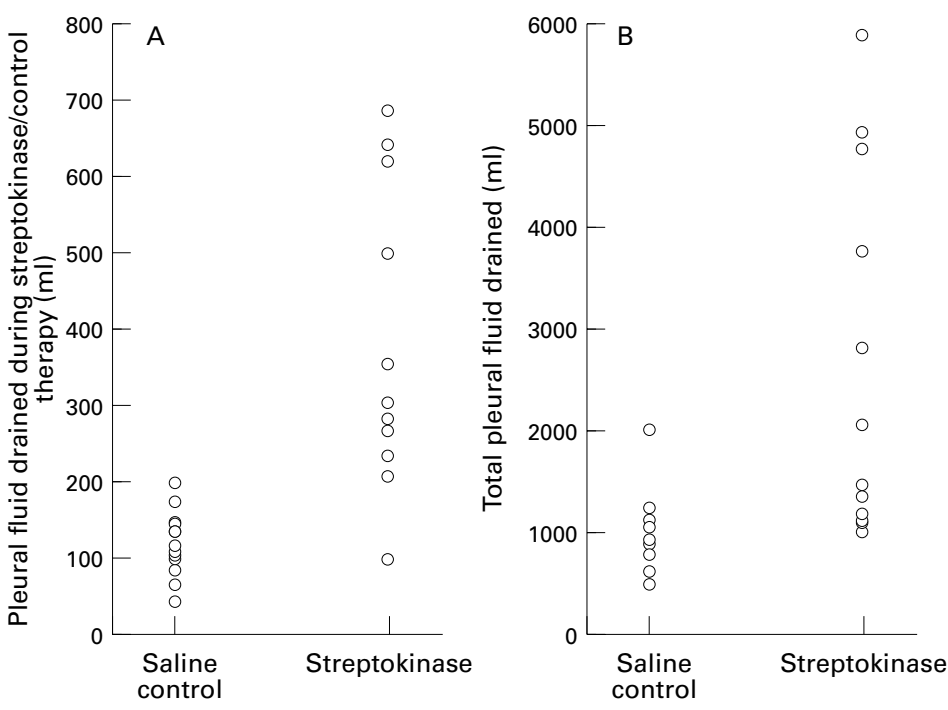

Figure 1 Volumes of pleural fluid drained by each subject in the two study groups. In $(A)$ the volume of fluid drained during the days of treatment with streptokinase or control saline are compared and in (B) the total volumes of pleural fluid drained in the individual patients are shown. The differences between the groups are statistically and physiologically significant. end points relating to pleural drainage, the number of pleural procedures required to control the fluid (streptokinase median 1, 95\% range $1-2$; control median $2,95 \%$ range $1-3$; $\mathrm{p}<0.05$, Mann-Whitney $U$ test) and the total duration of pleural drainage in the two groups were similar (streptokinase 8.9 (4.7) days versus control 8.72 (2.6) days; difference $0.1,95 \%$ $\mathrm{CI}-3.04$ to $3.4, \mathrm{p}=\mathrm{NS}$ ).

IMPROVEMENT IN THE CHEST RADIOGRAPH

The radiographic end points were also primary study end points. The reduction in the largest linear dimension of the pleural fluid collection was greater in the streptokinase treated group than in the control group (streptokinase 6.0 (2.7) $\mathrm{cm}$ versus control $3.4(2.7) \mathrm{cm}$; difference $2.6,95 \%$ CI 0.3 to $4.9, \mathrm{p}<0.05)$. The reduction in the overall estimated size of the pleural collection on the chest radiograph was greater in the streptokinase treated group than in the control group. At discharge 10 of 12 streptokinase treated subjects showed a $>75 \%$ improvement in the size of their pleural collection while only four of the nine assessable control

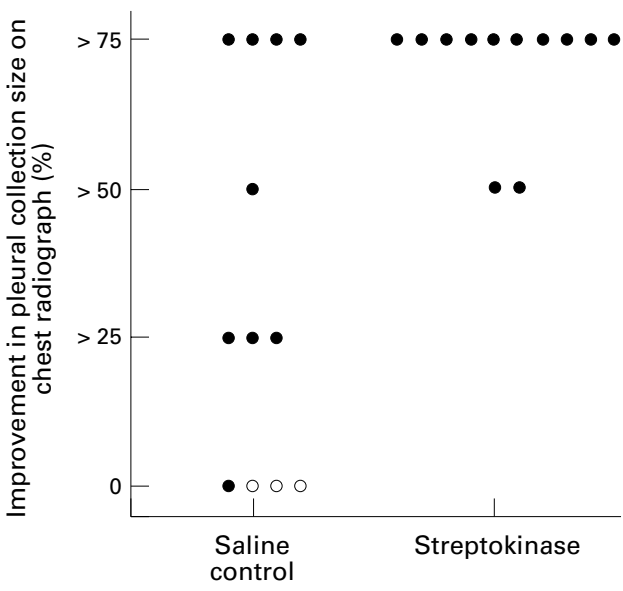

Figure 2 Percentage improvement in the size of the pleural opacity on the chest radiograph from entry into the study to discharge from hospital for all the subjects who completed the protocol. The improvement was consensus scored by two radiologists who were unaware of the subject's randomisation status. The three empty circles represent the three control subjects withdrawn for surgery in whom pleural drainage was poor. The differences between the groups are statistically and physiologically significant. 

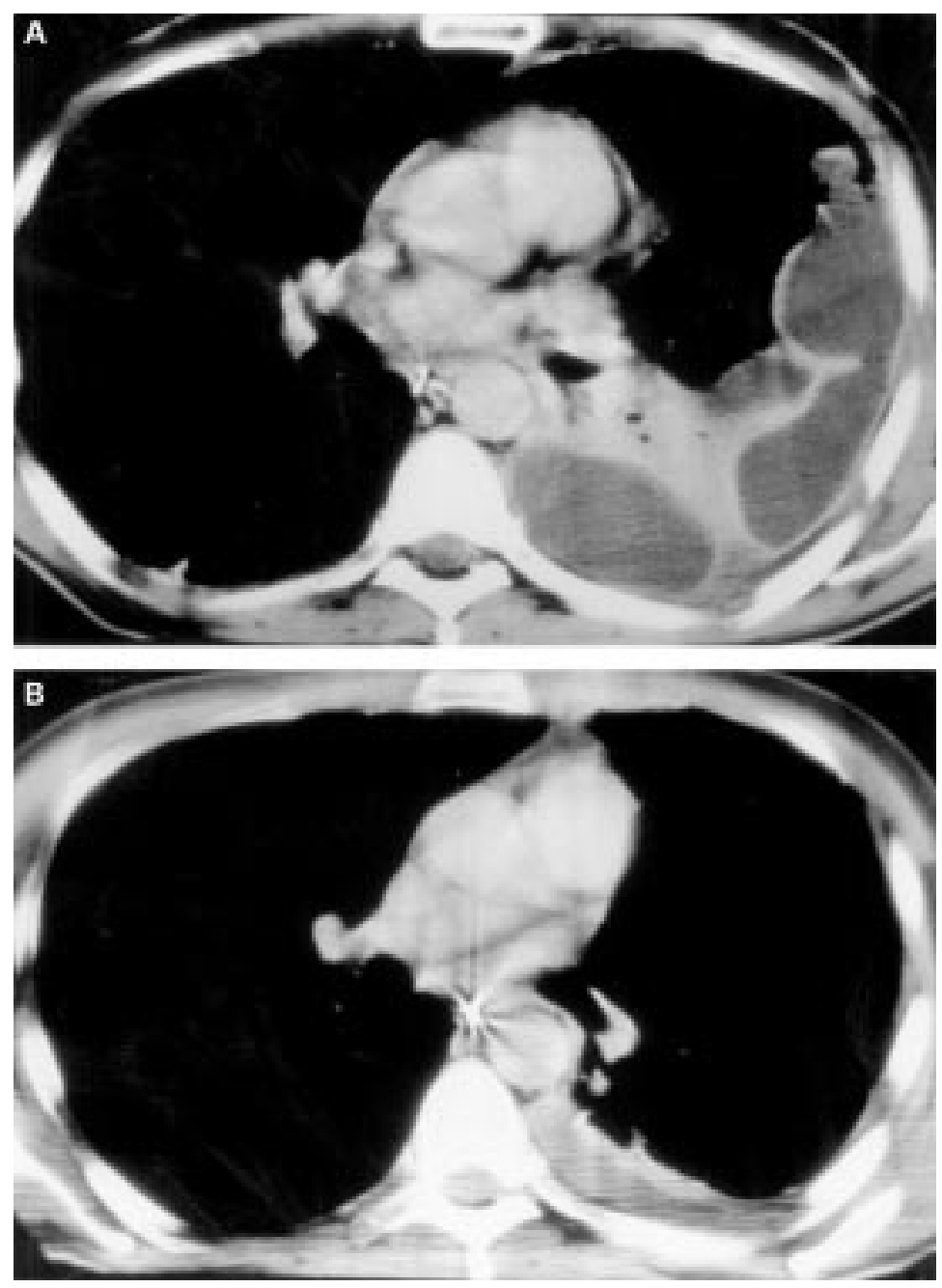

Figure 3 Thoracic CT scans of a subject with a multiloculated purulent empyema $(A)$ at diagnosis and (B) after three days of treatment with intrapleural streptokinase.

subjects showed a $>75 \%$ improvement (fig 2). Assuming that the three subjects withdrawn for surgery had not shown a $>75 \%$ overall radiographic improvement (the definition of withdrawal for surgery included "the presence of a substantial residual pleural collection" see protocol), the improvement in the streptokinase treated group was significantly greater than in the control group $(\mathrm{p}<0.05$, two-tailed Fisher's exact test). Resolution of a severely loculated empyema with intrapleural streptokinase is illustrated in fig 3.

SYSTEMIC FIBRINOLYSIS AND HAEMORRHAGE Measurement of the blood prothrombin ratio (INR) at baseline and daily during strepto-

Table 2 Mean (SD) prothrombin ratios expressed as the International Normalised Ratio (INR) at entry into the study (baseline) and averaged over the period of treatment with intrapleural streptokinase or control therapy

\begin{tabular}{lllll}
\hline & Baseline & $\begin{array}{l}\text { Streptokinase/control } \\
\text { treatment period }\end{array}$ & $\begin{array}{l}\text { Difference } \\
\text { (95\% CI) }\end{array}$ & $\begin{array}{l}\text { p value } \\
\text { (paired t test) }\end{array}$ \\
\hline $\begin{array}{l}\text { Streptokinase } \\
\text { group ( } \mathrm{n}=6)\end{array}$ & $1.25(0.13)$ & $1.29(0.14)$ & $\begin{array}{l}0.08(0.22) \\
(-0.06 \text { to } 0.22)\end{array}$ & $\mathrm{NS}$ \\
$\begin{array}{l}\text { Control group } \\
(\mathrm{n}=6)\end{array}$ & $1.18(0.08)$ & $1.32(0.14)$ & $\begin{array}{l}0.14(0.12) \\
(0.64 \text { to } 0.22)\end{array}$ & $<0.05$ \\
\hline
\end{tabular}

kinase/control therapy was performed in six subjects in each study group. During the days of streptokinase/control therapy the average prothrombin ratio (INR) was a little higher than at baseline in the control group. This rise was statistically but not physiologically significant (table 2). In the streptokinase group there was no rise in systemic INR, and no subject exhibited physiologically significant systemic fibrinolysis (highest INR $=1.5$ in both groups). There were no local pleural or systemic haemorrhagic problems in either group.

SURGERY AND CLINICAL PROGRESS

In the control group three patients were withdrawn from the study and referred for surgery. In the streptokinase group no patients required surgery. Two patients (one in each treatment group) had an underlying bronchial carcinoma identified during later investigation.

The duration of the hospital stay among the patients completing the protocol and the time to normalisation of the total white blood cell count, blood levels of $\mathrm{C}$ reactive protein, and temperature were similar (table 3 ).

\section{Discussion}

This study reports the results of a randomised controlled trial to assess the efficacy of intrapleural streptokinase in the drainage of infected pleural effusions. Effective pleural drainage is a primary aim of treatment in this condition. ${ }^{10}$ The primary end points of this study show that streptokinase improves the catheter drainage of such pleural collections in terms of increased pleural fluid flow and improvement in the chest radiograph by discharge from hospital. This benefit was achieved without significant systemic fibrinolysis and was not associated with local or systemic haemorrhage.

The study groups did not differ significantly in any of their baseline characteristics (table 1). Despite this there is a trend towards more severe disease in the group receiving streptokinase (who ultimately had the better outcome). The streptokinase group included more patients with overtly purulent pleural fluid and their average baseline pleural collection size was larger. Since a larger pleural collection has a poorer prognosis than a smaller collection, ${ }^{3}$ this strengthens the evidence for the efficacy of streptokinase in this study.

We have studied a population with community acquired parapneumonic pleural effusions exhibiting the clinical, biochemical, and anatomical characteristics of secondary pleural infection. ${ }^{14-8}$ In 13 of the subjects (54\%) the fluid was either frankly purulent or Gram stain or culture positive. In two of these the pleural fluid was Gram stain and/or culture positive but not overtly purulent, which confirms that frank purulence is a late feature of pleural sepsis ${ }^{9}$ and is insensitive if used as the only index of infection. In the other 11 cases the fluid was either loculated, confirming fibrinous pleurisy (and hence infection related inflammatory disturbance of pleural fibrin meta- 
Table 3 Mean (SD) time to normalisation of the clinical end points, the total duration of hospital stay, and the total duration of pleural drainage in the two groups

\begin{tabular}{lccc}
\hline & $\begin{array}{c}\text { Streptokinase } \\
(n=12)\end{array}$ & $\begin{array}{l}\text { Control } \\
(n=12)\end{array}$ & $\begin{array}{l}\text { Difference } \\
\text { (95\% CI) }\end{array}$ \\
\hline Duration of pleural drainage (days) & $9(5)$ & $9(3)$ & $0.0(-3.49$ to 3.49) \\
Duration of hospital stay (days) & $16(13)$ & $13(8)$ & $3.0(-6.14$ to 12.1) \\
Time to normal white blood cell count (days) & $9(11)$ & $5(7)$ & $4.0(-3.81$ to 11.8$)$ \\
Time to normal bood C reactive protein (days) & $34(10)$ & $27(17)$ & $7.0(-4.81$ to 18.8) \\
Time to temperature normal consistently (days) & $6(6)$ & $8(6)$ & $-2.0(-7.08$ to 3.08) \\
\hline
\end{tabular}

The differences between the two groups were all non-significant.

bolism $^{4}$ ), and/or met the biochemical criteria which indicate secondary infection and the need for pleural drainage. ${ }^{6}$ As well as indicating infection, fibrinous fluid loculation predicts failed catheter drainage since the loculation impedes free drainage ${ }^{22}$ and for this reason this was included as one of the study entry criteria. All the studied subjects fulfilled more than one of the entry criteria, and 17 of the $24(71 \%)$ fulfilled three or more.

The accepted mainstay of the treatment of pleural infection is pleural drainage and this study was designed to assess the effect of streptokinase on this and not on overall mortality or the need for later surgery. Despite this there is a trend towards less surgery in the streptokinase group with none of these subjects, and three control subjects, requiring surgery. This difference means the radiological end point based on the maximum dimension of the pleural collection (which is already significantly in favour of streptokinase) is conservative because radiological data were only available for those subjects who did not die or require surgery before discharge (when the second set of radiographs for this analysis were taken). Those withdrawn for surgery before this were the poorer responders and so the control group as a whole probably faired even worse than this analysis suggests. The assessment of the other radiological end point - the overall reduction in chest radiographic pleural collection size does allow for this bias. It can be assumed that the three patients withdrawn for surgery did not show a $>75 \%$ improvement in their radiographs since the criteria for surgery included "the presence of a substantial residual pleural collection". When these three subjects are included in the analysis the overall reduction in the radiographic size of the empyema is statistically significant as well as being clearly clinically significant (fig 1).

There was no evidence of a systemic fibrinolytic action from the intrapleural streptokinase. In fact, there was a small, statistically significant but physiologically insignificant rise in INR from baseline in the control group which was not seen in the streptokinase group (table 2). This small rise in the control group is probably attributable to the systemic effects of sepsis and its absence in the streptokinase group may be indirect evidence of a systemic improvement in sepsis control in this group.

This study suggests that the use of intrapleural streptokinase may be beneficial at the diagnosis of a complicated parapneumonic effusion and not just as "rescue" therapy when standard drainage has failed. This is a significant difference from previous reports. ${ }^{12-19}$
Early treatment has both potential advantages and disadvantages. More effective pleural drainage might be achieved by intervening before severe pleural adhesions develop; animal work supports this hypothesis. ${ }^{20}$ On the other hand, early treatment could have been detrimental by increasing pleural fluid production ${ }^{23}$ in subjects who would have drained adequately without streptokinase. This study shows that overall there is an improvement in pleural drainage when streptokinase is used as early treatment.

This study is the first randomised controlled trial of the use of a fibrinolytic agent to drain an infected fluid collection ("enzymatic debridement"). Small case series have reported a similar approach in several other clinical situations including ocular hyphaema, ${ }^{24}$ intracerebral haematoma, ${ }^{25}$ loculated pericardial effusion, ${ }^{26}$ and various abscesses. ${ }^{2728}$ The efficacy of intrapleural streptokinase in this study provides general support for this novel approach. Fibrinolytic "enzymatic debridement" may evolve to reduce the need for drainage surgery in many common situations.

In conclusion, this study has shown that intrapleural streptokinase at a dose of 250000 IU daily for three days is safe and effective in improving the catheter drainage of infected pleural effusions. It suggests it may be a useful aid in the management of this disorder.

1 Light RW, Girard WM, Jenkinson SG, George RB. Parapneumonic effusions. Am f Med 1980;69:507-12.

2 Taryle DA, Potts DE, Sahn SA. The incidence and clinical correlates of parapneumonic effusions in pneumococcal pneumonia. Chest 1978;74:170-3.

3 Ferguson AD, Prescott RJ, Selkon JB, Watson D, Swinburn CR, Empyema subcommittee of the Research Committee of the British Thoracic Society. The clinical course and management of thoracic empyema. $Q \mathcal{F}$ Med 1996;89: $285-9$.

4 Idell S, Girard W, Koenig KB, McLarty J, Fair DS. Abnormalities of pathways of fibrin turnover in the human
pleural space. Am Rev Respir Dis 1991;144:187-94.

5 Potts DE, Levin DC, Sahn SA. Pleural fluid pH in parapneumonic effusions. Chest 1976;70:328-3

6 Light RW, MacGregor MI, Ball WCJ, Luchsinger PC. Diagnostic significance of pleural fluid $\mathrm{pH}$ and $\mathrm{PCO}_{2}$. Chest 1973;64:591-6.

7 Sahn SA, Reller LB, Taryle DA, Antony VB, Good JTJ. The contribution of leukocytes and bacteria to the low pH of empyema fluid. Am Rev Respir Dis 1983;128:811-5.

8 Potts DE, Taryle DA, Sahn SA. The glucose-pH relationship in parapneumonic effusions. Arch Intern Med 1978;138: 1378-80.

9 Sahn SA. Management of complicated parapneumonic effusions. Am Rev Respir Dis 1993;148:813-7.

10 Kaplan DK. Treatment of empyema thoracis. Thorax 1994; 49:845-6.

11 Tillett WS, Sherry S. The effect in patients of streptococcal fibrinolysin (streptokinase) and streptococcal desoxyribonuclease on fibrinous, purulent, and sanguinous ribonuclease on fibrinous, purulent, and sang

12 Aye RW, Froese DP, Hill LD. Use of purified streptokinase in empyema and hemothorax. Am f Surg 1991;161:560-2. in empyema and hemothorax. Am f Surg 1991;161:560-2.
Henke CA, Leatherman JW. Intrapleurally administered streptokinase in the treatment of acute loculated nonpurulent parapneumonic effusions. Am Rev Respir Dis 1992;145:680-4.

14 Alfageme I, Munoz F, Pena N, Umbria S. Empyema of the thorax in adults. Etiology, microbiologic findings, and management. Chest 1993;103:839-43. 
15 Willsie Ediger SK, Salzman G, Reisz G, Foreman MG. Use of intrapleural streptokinase in the treatment of thoracic empyema. Am f Med Sci 1990;300:296-300.

16 Bergh NP, Ekroth R, Larsson S, Nagy P. Intrapleural streptokinase in the treatment of haemothorax and empyema. Scand $\mathcal{F}$ Thorac Cardiovasc Surg 1977;11:265-8

17 Ogirala RG, Williams MHJ. Streptokinase in a loculated pleural effusion. Effectiveness determined by site of instillation. Chest 1988;94:884-6.

18 Bouros D, Schiza S, Panagou P, Drositis J, Siafakas N. Role of streptokinase in the treatment of acute loculated parapneumonic pleural effusions and empyema. Thorax 1994;49:852-5.

19 Taylor RFH, Rubens MB, Pearson MC, Barnes NC. Intrapleural streptokinase in the management of empyema. Thorax 1994;49:856-9.

20 Strange C, Baumann MH, Sahn SA, Idell S. Effects of intrapleural heparin or urokinase on the extent of tetracycline-induced pleural disease. Am $\mathcal{F}$ Respir Crit Care Med 1995;151:508-15.

21 van Sonnenberg E, Nakamoto SK, Mueller PR, et al. CTand ultrasound-guided catheter drainage of empyemas after chest-tube failure. Radiology 1984;151:349-53.
22 Poe RH, Marin MG, Israel RH, Kallay MC. Utility of pleural fluid analysis in predicting tube thoracostomy/ decortication in parapneumonic effusions. Chest 1991; 100:963-7.

23 Strange C, Allen ML, Harley R, Lazarchick J, Sahn SA. Intrapleural streptokinase in experimental empyema. Am Rev Respir Dis 1993;147:962-6.

24 Leet DM. Treatment of total hyphemas with urokinase. $A m$ f Ophthalmol 1977;84:79-84.

25 Schaller C, Rohde V, Meyer B, Hassler W. Stereotactic puncture and lysis of spontaneous intracerebral hemorrhage using recombinant tissue-plasminogen activator. orrhage using recombinant tissu

26 Winkler WB, Karnik R, Slany J. Treatment of exudative fibrinous pericarditis with intrapericardial urokinase. Lancet 1994;344:1541-2.

27 Griebling TL, Chang PJ, Loening SA, Williams RD. Percutaneous thrombolysis of an infected retroperitoneal hematoma with urokinase. 7 Urol 1995;154:1477

28 Lahorra JM, Haaga JR, Stellato T, Flanigan T, Graham R. Safety of intracavitary urokinase with percutaneous abscess drainage. AfR 1993;160:171-4. 